\title{
A prática de birdwatching para o desenvolvimento de Tecnologia da Informação Verde
}

\section{Thais Rocha de Oliveira ${ }^{1}$, Paulo Urbano Avila ${ }^{2}$, David Steinwender ${ }^{3}$}

${ }^{1}$ Fundação Getúlio Vargas. Av. Teixeira e Souza, 1111. Centro. Cabo Frio-RJ, Brasil (CEP 28907-410). E-mail: thaisrocholi.rj@gmail.com.

${ }^{2}$ Faculdade Sumaré. Av. Dr. Arnaldo, 1793. São Paulo-SP, Brasil (CEP 01255-000).

${ }^{3}$ Universidade Veiga de Almeida. Estrada Perynas, s/n. Perynas. Cabo Frio-RJ, Brasil (CEP 28909-000).

Resumo. Este artigo se desenvolve a partir de um estudo sobre a origem da observação da Natureza para o desenvolvimento de tecnologias, utilizando como metodologia o estudo da semiótica, com o intuito de fomentar a prática da atividade de birdwatching nas empresas. Para isso, foi feito uma reflexão acerca dos aspectos históricos e filosóficos dentro do pensamento de Aristóteles e Platão e de que modo pode-se criar uma consciência ecológica para desenvolver tecnologias sustentáveis (TI Verde). Tem-se como objetivo geral aumentar o conhecimento sobre a situação das espécies de aves identificadas, gerando informações a pesquisadores, universidades, escolas e empresas que trabalhem com o tema Sustentabilidade e Responsabilidade Social.

Palavras-chave: Natureza; Semiótica; Birdwatching; Tecnologias sustentáveis; Filosofia da Tecnologia.

Abstract. The practice of birdwatching for the development of Green Information Technology. This article is developed from a study on the origin of the observation of Nature for the development of technologies, using as methodology the study of semiotics, with the purpose of promoting the practice of birdwatching activity in companies. For this, a reflection was made on the historical and philosophical aspects within the thinking of Aristotle and Plato and how an ecological consciousness can be created to develop sustainable technologies (Green IT). The general objective is to increase knowledge about the situation of the identified bird species, generating information for researchers, universities, schools and companies that work on the theme Sustainability and Social Responsibility.

Keywords: Nature; Semiotics; Birdwatching; Sustainable technologies; Philosophy of Technology.
Recebido:

$24 / 07 / 2018$

Aceito:

$30 / 08 / 2018$

Publicado:

$31 / 08 / 2018$

Acesso aberto

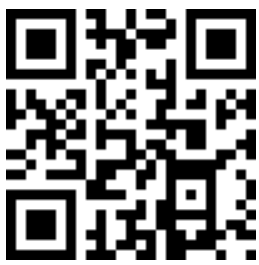

ORCID

(D) 0000-0003-4381-2044

Thais Rocha de

Oliveira

() 0000-0002-8268-5247

Paulo Urbano Avila

D 0000-0001-6949-617X

David Steinwender 


\section{Introdução}

As aves fazem parte da vida da humanidade desde a criação do mundo. No período pré-histórico, os seres humanos já as contemplavam, ao olhar para o céu acompanhando seu pouso, representando-as em pinturas rupestres. Na Grécia entre os séculos VIII e IX a.C. as espécies eram descritas de um modo real e imaginário nos manuscritos de Hesíodo e Homero (Costa, 2007).

Tem-se relatos de que a prática da observação de aves foi desenvolvida na Inglaterra no século XVIII como lazer da aristocracia, popularizando-se nos Estados Unidos em 1873, com a fundação da primeira organização para observação e estudo das aves: a Nutall Ornitological Club (Mourão, 1999).

Conforme Mourão (1999), esta prática vem aumentando de modo gradativo no Brasil, desde as fundações dos clubes de observadores de aves (década de 1970 e 1980), especialmente quando se destacou no início da realização de eventos o Avistar, Feira de Observação de Aves, em 2006. O empreendimento que era quase que exclusivamente de ornitólogos, passou a ser mais conhecido e divulgado pela mídia.

Acredita-se na prática educativa de observação de aves como um ato importante para o desenvolvimento de estratégias para alterar a relação ser humano-Natureza, que tem sido predominantemente de base exploratória, além de haver situações de descartes desencadeando impactos diretamente no meio ambiente. Tal degradação acarretada pela ação humana sobre o meio ambiente pode ser avaliado pelas medições de metais pesados nos solos, plantas e animais, uma vez que a poluição por metais afeta diretamente a densidade e a diversidade de comunidades pertencentes à vida, sobretudo os humanos e animais (Mountouris et al., 2002). Deste modo, a avaliação de poluentes, em diversos componentes do ecossistema passou a ser uma tarefa importante para prevenir o risco para a vida natural e saúde pública (Gragnaniello et al., 2001).

Dado ao que acontece, as aves são largamente estudadas como bioindicadores, por estarem no topo da cadeia alimentar, sofrerem vulnerabilidade a produtos tóxicos, além de responderem por mudanças sutis no ambiente, principalmente por motivo da sua alta taxa metabólica. Poluição por metais pode causar danos na disfunção reprodutiva das aves, com diminuição no tamanho da ninhada, diminuição da fertilidade, falha na incubação e desbate da casca de ovo (Edens e Garlich, 1983; Heinz, 1996), gerando também uma maior predisposição para que se desenvolva doenças e estresse, tais como, alterações comportamentais.

A vista disso, considera-se necessário pensar em estratégias didáticas para relacionar a prática de birdwatching com a tecnologia, dado que ao se descobrir uma tecnologia, logo a tecnologia antiga é descartada e vai para o lixo. É conveniente que o descarte destes materiais não sejam desperdiçados, mas reutilizados para construção de novas tecnologias, pois o contrário do que se pode imaginar, são altamente contaminantes do meio ambiente e à vida. Ferreira (2009) ressalta que a TI Verde faz menção ao conceito de ecoeficiência, onde sua origem remete à década de 1980, consistindo na utilização eficiente dos recursos naturais.

O foco principal da Tecnologia da Informação Verde é apresentar um meio melhor de se evoluir tecnologicamente de forma sustentável. A prática de birdwatching visa a integrar diferentes conhecimentos a respeito de aves, com o intuito de se comprometer a desenvolver uma base tecnológica a partir desta perspectiva da TI Verde, com o fomento de uma visão empreendedora por parte da integração Universidade/Empresa. 


\section{Física, meio ambiente e os fundamentos da estética \\ 0 conceito de Natureza não diz} respeito apenas ao que é externo ao homem, todavia abrange o que lhe é interno e útil para que se possa articular o ponto de partida com o todo atribuindo um sentido cósmico que corresponda à existência humana; um sentido de ser parte do mundo.

Freitas (2005) sinaliza o olhar para a transdisciplinalidade da estética moderna inaugura seus pilares como partes teóricas fundadas em problemas peculiares relacionadas à existência do ser humano, bem como sua formação e seu dinamismo dentro do sistema socioeconômico, considerando seus fenômenos mentais e predominância dos seus desejos nos processos que estabelecem uma ligação com a natureza das coisas, sobretudo indo contra a ordem social e a projeção cósmica da natureza, tal como explicitado nas produções filosóficas de Schopenhauer, Marx, Freud, Heidegger e Einstein. Isto aponta para os fundamentos do quadro da história da humanidade que compreende a multiplicidade cultural que engloba os processos sociais e econômicos.

0 pensamento dominante da matriz da estética da vida projetada no ser humano, conforme pesquisa de Freitas (2005) está amarrada no determinismo e no aprimoramento genético do ser humano; ideias que partiram de Newton e Darwin. A inversão disforme e amputadora dos princípios que embasam os estudos desses cientistas, tal como, "Princípios matemáticos da filosofia natural" e "A origem das espécies" para os sistemas sociais e econômicos, ajudou a dar significado ao processo civilizatório organizado acerca das origens que desencadearam acúmulo e o individualismo, síntese que desencadeou a acelerada solidificação e propagação do capitalismo durante os séculos XIX e XX, inserindo categoricamente o etnocentrismo, as mazelas e a degradação ambiental do planeta. Essa crise planetária é bastante complexa, pois deu um impulso para que se articule as ciências naturais com os grandes sistemas econômicos e políticos mundiais, causando como efeito a irradiação planetária tal como ocorre nos países centrais.

No entanto, de forma alguma se concebe a ideia de uma produção tecnológica isenta de uma análise ética e moral para sua utilização, não considerando as reais necessidades da sociedade. Ao passo que atenta-se para a ideia de que o avanço científicotecnológico pode ser refletido dentro de uma ótica diferente e motivadora.

É dentro desta concepção, que neste artigo procura-se apresentar que tanto a ciência como a tecnologia, podem alterar certos quadros que tem imperado no cenário ambiental mundial, indo mais adiante, deve-se pensar sobre como o processo de produção de ciência e tecnologia pode ser concedido com consciência e utilidade social.

\section{Reflexões históricas sobre a filosofia aplicada à educação}

0 termo ensino (en-sin-o), deriva do latim signum, marca distintiva, sinal (Heckler et al., 1984), de onde está a origem da palavra signo, desenho, desígnio, senha, significação, sina, sino, et cetera, ou seja, é uma família numerosa. Pode-se ainda levar esta família à origem de secare, cortar (fazer sinais por incisão). Estudar, por sua vez, deriva do latim studere, ser zeloso, guardar com cuidado (Heckler et al, 1984).

De acordo com Oliveira (2018), a formação dos profissionais da área da tecnologia deve se firmar nos pressupostos de sustentabilidade que

\footnotetext{
“... deve privilegiar novas propostas pedagógicas interdisciplinares, em que a visão integrada, sistêmica e holística substitua os projetos pedagógicos disciplinares dentro da inércia de uma realidade fragmentada" (Oliveira, 2018).
} 
Ao lado dos fenômenos naturais, do material tecnológico e dos artigos de consumo, existe um universo em particular, o universo de signos. Ali onde o signo se encontra, encontra-se também o ideológico. Tudo que é ideológico possui um valor semiótico (Bakhtin, 2010).

Com esta intenção propõe-se para as empresas, o incentivo da prática de birdwatching como atividade recreativa para despertar o lado criativo de seus colaboradores, afim de que por meio da representação semiótica ligada a observação, se passe a criar novas tecnologias. A observação de aves no Brasil ainda é pouco praticada e o ensino tecnológico, está muito vinculado ao livro didático, sendo o conteúdo apresentado com pouca história e descontextualizado da realidade.

A educação tem por objeto suscitar e desenvolver, no indivíduo, certo número de estados físicos, intelectuais e morais, reclamados pela sociedade política no seu conjunto e pelo meio especial a que o indivíduo, particularmente, se destine.

Para ter-se uma maior clareza sobre preservação ambiental aplicando a tecnologia a favor da preservação das espécies, é necessário contextualizar a história e a filosofia. De acordo com Abrão (2004), o período Clássico teve como principais pensadores, Sócrates, Platão e Aristóteles, filósofos responsáveis pela construção da estrutura do nosso conhecimento. No apogeu da civilização grega, Sócrates, Platão e Aristóteles, causaram influências profundas na alteração da definição de Natureza. Nesse período, houve a separação do Homem e Natureza, corpo e alma, sujeito e objeto, estabelecendo a origem do antropocentrismo.

Battestin e Ghiggi (2011) ressaltam que um dos problemas que preocupou os filósofos gregos foi o fluxo da Natureza. Para Platão, todas as coisas que se pode tocar e sentir na natureza tende a fluir, tendo como uma forma eterna e imutável. Platão fez uma divisão da realidade em duas partes, a primeira parte se refere ao mundo dos sentidos, tal como, conhecimento aproximado ou imperfeito, e a outra parte se refere ao mundo das ideias, onde obtêm-se um conhecimento seguro utilizando a razão. Tal como Platão, Aristóteles representou um avanço significativo para a história da Ciência, ao observar a Natureza a partir de uma ótica sistemática, sua contribuição foi o desenvolvimento de teorias habilidosas sobre muitas áreas da Ciência e da Filosofia.

Conforme Grün (1996), a ideia aristotélica da natureza, representa algo alegre e vivo, onde as espécies procuram concretizar seu processo natural, que ao serem observadas tem-se a ideia de se copiar para uma natureza inorgânica. 0 período Medieval também foi marcante para a humanidade. Na Idade Média as comunidades eram pequenas e a crença principal que se tinha era de que o tempo pertencia a Deus. Esse período foi o marco de grandes mudanças e revoluções, como a física e a astronomia, foi o período da grande revelação de Copérnico, Galileu e Newton. Nicolau Copérnico descobriu que a Terra era um planeta, deixando, portanto, de ser o centro do universo. Galileu partiu da hipótese de que apenas a experiência pode ser fonte de conhecimento para explicar os fenômenos da natureza.

Em sua obra Discursos e Demonstrações Matemáticas acerca de Duas Novas Ciências (1638) Galileu expõe um diálogo bastante enriquecedor entre três interlocutores: Salviati, o próprio Galileu, sábio experimentador; Sagredo, o homem prático, de mente progressiva, sem raízes ou crenças, e Simplicio, apresentador de uma perspectiva aristotélica de professor dogmático, defensor das velhas teorias, perscrutando de todas as formas, fundir as teorias reformuladas com as teorias aristotélicas segundo relatos de Battestin e Ghiggi (2011).

No artigo de Orsi (2015) há um estudo acerca do voo dos pássaros apontando que os pássaros utilizam o 
campo magnético da Terra para se orientar, fazendo uma descrição dos experimentos, onde a aplicação de campos magnéticos artificiais impôssibilitavam o sentido de direção das aves, em condições de laboratório. Dado que algumas aves, como os pombos, possuem partículas magnéticas no bico. Logo, foi feito um experimento a pouco tempo atrás, em que a conexão dessa região com o cérebro foi interrompida, mas apesar disso, alguns pássaros conseguem se direcionar.

Conforme pesquisa de Lepore et al. (2017) cientistas da Universidade de Cambridge (Reino Unido) e de Trento (Itália) fizeram uma descoberta acerca da eficiência do trabalho das aranhas de forma com que suas teias sejam tecidas com uma seda muito mais forte e resistente. Com tal afinco, Lepore et al. (2017) passaram a observar a tecelagem das aranhas para em seguida borrifar em suas casas uma solução contendo grafeno e de nanotubos de carbono, dois componentes bastante resistentes e fortes. Ao absorverem o componente, as aranhas permaneceram como habitualmente se comportavam. Até que ao serem coletadas suas as teias pelos cientistas, desde o momento da borrifação do líquido dos nanomateriais, contrapondo o resultado com as tecelagens das mesmas aranhas antes da borrifação, o resultado apresentado, foi que as novas teias tiveram um aumento considerável de força, tenacidade e elasticidade dos fios, denominado pela equipe de "biocompósitos" - materiais compostos sintetizados biologicamente.

Avila et al. (2018) destaca que a observação da Natureza, como inspiração visando a constituir novos conceitos para se criar produtos industriais é baseado no conhecimento biológico. 0 design ecológico é resultado deste olhar para a natureza, ou seja, da ideia de se trabalhar com os recursos que pertencem a uma determinada região geográfica beneficiando a biodiversidade, bem como os saberes acumulados pelas gerações que nela habitam.
Para Capra (2003), os principais aspectos do período Medieval diz respeito de que antes de 1500 , a visão de mundo dominante na Europa, assim como na maioria das outras civilizações, era orgânica. As pessoas habitavam comunidades pequenas e coesas, e tinham como vivência uma natureza em termos de relações orgânicas, apontando para a principal característica de uma interdependência dos fenômenos espirituais e materiais, bem como a subordinação das necessidades individuais às da comunidade.

[...] A natureza da ciência medieval nesse período era a visão de mundo dominante, o Teocentrismo, onde Deus era considerado o centro de tudo. BATTESTIN \& GHIGGI v(3), diferente da ciência contemporânea, baseava-se na razão e na fé, e sua principal finalidade era compreender o significado das coisas e não exercer a predição ou o controle. Os cientistas medievais, [...] consideravam do mais alto significado as questões referentes a Deus, à alma humana e à ética (Capra, 2003, p. 49).

Todas estas questões juntas buscavam identificação das variáveis que acontecem na relação do Homem com a Natureza. A fé que o homem colocava na ciência e nas suas grandes invenções, causou grandes transformações nos modos de se viver. Nesta perspectiva, a Natureza passou a ser instrumentalizada e o desenvolvimento da técnica predominou, indo de encontro com seu próprio método, desvinculando-se da reflexão filosófica.

Com a busca de fundamentos sobre a relação do Homem com a Natureza, ficam claras as mudanças ocorridas no decorrer dos tempos. Todavia, um dos períodos históricos mais desafiadores para a humanidade, foi o Período Moderno. Com frequência os historiadores da Filosofia apontam esse período como Filosofia Moderna, sendo o saber que se desenvolve na Europa 
durante o século XVII. Outros pesquisadores ressaltam que a Filosofia Moderna representa o início de uma autêntica busca pelo saber, pela técnica. Logo, a Revolução Industrial foi um marco para que se mudassem os modos de produção, conforme especificado no tópico abaixo.

\section{Revolução industrial e questões ambientais afetadas pelo consumo exagerado}

A Revolução Industrial não apenas transformou a capacidade humana de modificar a natureza, mas também alterou as formas de produção do homem e em decorrência disto, da produtividade, tornando mais acessível os produtos e os processos de produção. Deste modo, milhares de pessoas tiveram a possibilidade de comprar produtos que antes eram exclusividades da elite.

Quando se consome em demasia, raramente se pensa no impacto ambiental causado pelo produto, a começar pelo processo da retirada da matéria prima, com toda poluição gerada pela indústria, transporte e comércio até chegar ao consumidor final.

Quando se aumenta o consumo, consequentemente se tem um aumento de produção, para alcançar os desejos da demanda, de igual modo, cresce a extração de recursos naturais. As sequelas deixadas por este processo são os desmatamentos das maiores áreas para cultivar a agricultura. Nessa situação, muitas espécies entram em extinção, trazendo consigo consequências graves, como o desequilíbrio na cadeia alimentar, os recursos hídricos, com dejetos oriundos das indústrias e fábricas, esgoto e agrotóxicos que são irreversivelmente poluidores.

O descarte de resíduos sólidos ocasionado pelo ser humano e empresas, geralmente é irrefletido. Contudo, quando há um grande volume empresarial, coloca-se em evidência o desperdício, que dentro do contexto residencial, é fator de consumismo. Por isso, a medição de lixo pode apontar para um consumismo desordenado na sociedade (Giacomini Filho, 2008).

0 setor tecnológico destas quase duas décadas do século XXI tem repercutido mundialmente quando se aponta para os impactos ambientais ao se extrair matéria prima do meio ambiente, tal e qual os efeitos causados pela poluição dos recursos naturais.

Pesso (2004) faz uma estimativa de que, para cada computador pessoal pesando em torno de $24 \mathrm{~kg}$, seriam despendidos $240 \mathrm{~kg}$ de combustível fóssil, $22 \mathrm{~kg}$ de produtos químicos e 1.500 litros de água. Logo, tem-se a informação de que cerca de 150 milhões de computadores são fabricados ao ano em todo mundo.

Com os avanços tecnológicos, há uma grande oferta de produtos industrializados, cuja influência da mídia afeta diretamente o consumismo desenfreado. Os produtos têm uma durabilidade menor, em razão de que a indústria produz inovação quase que diariamente, modernizando com a obsolescência planejada, substituindo, descartando e poluindo com o lixo.

Aponta-se como relevância à conscientização em virtude de fomentar a criação e trazer ao Brasil tecnologias sustentáveis neste século XXI, pois a cada ano que se passa é acelerado o uso destas. Para tanto, as empresas necessitam pensar sobre o tamanho, desperdício e a contaminação do ecossistema que estão causando. Acredita-se que enxergar com outros olhos a importância da preservação do planeta é se enxergar como responsável por isso.

Deste modo, apresenta-se com relevância o objetivo geral deste trabalho que é aumentar o conhecimento sobre a situação das espécies de aves, gerando informações a pesquisadores, universidades, escolas e empresas que trabalhem com o tema Sustentabilidade e Responsabilidade Social e daquelas que gostariam de agregar como valor da empresa. Os objetivos específicos são despertar a consciência para a educação ambiental; desenvolver a criatividade 
para trabalhos com tecnologias verdes; criar harmonia grupal e ambiental.

\section{Metodologia}

Construiu-se este artigo lançando-se mão de uma abordagem qualitativa baseada numa pesquisa bibliográfica com técnica de análise de conteúdo. Para alcance dos objetivos ao que se pretende atender far-se-á uso das Metodologias Ativas incentivando e orientado o processo de desenvolvimento do aprendizado por meio de associação semiótica.

Entende-se aqui por semiótica o conceito adotado por Avila et al. (2018), derivado de Santaella (1983), como sendo

a ciência que tem por objeto de investigação todas as linguagens possíveis, ou seja, que tem por objetivo o exame dos modos de constituição de todo e qualquer fenômeno de produção de significação e de sentido ou, simplesmente, [...] é a ciência dos signos.

O trabalho está organizado com uma nova abordagem através da organização de grupos de funcionários das empresas de tecnologia, ampliando os conhecimentos sobre conservação ambiental relacionando-os aos aspectos de mimética tecnológica. Com tal característica, dentro de uma perspectiva semiótica, o pensamento de Aristóteles com relação à arte mimética desenvolve a atividade artística e recreadora da realidade, de uma forma mais esclarecedora. A mimese não é a representação de uma simples imitação, ao passo que expressa o agir dentro do contexto da poiesis grega, empregando a techné (técnica). Passa a ser uma atividade que supera a reprodução in aequo do real chegando mesmo a alterálo.

\section{Resultados e discussões}

Fernandes et al. (2014) apontam que o Brasil é considerado o segundo país do mundo com maior diversidade de aves, em virtude disso, tem crescido constantemente $\mathrm{o}$ interesse pela observação de pássaros. A atividade colabora de forma exponencial para trazer uma consciência de valor para natureza, especialmente para um maior senso de preservação da flora e fauna neste século XXI, dado que seu registro científico subsidia ações de gestão e educação ambiental, pois com sua catalogação dá para saber os hábitos florestais e a densidade populacional de cada espécie, bem como seu comportamento.

A observação com a catalogação das aves estabelece conexões nunca antes experimentadas com o meio ambiente e os habitat naturais, levando a consciência conceitos importantes relacionados à física, à biologia e à tecnologia, abraçando uma opinião a respeito da conservação que muitas vezes é negligenciada.

Um exemplo de como a prática da birdwatching pode ser importante e uma estratégia inovadora nas empresas brasileiras pode ser inspirada pelo relato de Arruda (2011) que informa que no Japão, alguns trens-balas eram capazes de atingir a velocidade de $300 \mathrm{~km} / \mathrm{h}$, porém o sonido dos trens ultrapassava os padrões ambientais de poluição sonora. Assim, descobriu-se que um dos motivos desse resultado indesejável era a onda de pressão atmosférica gerada pelo trem, no momento em que entrava em um túnel estreito. 0 resultado na saída do túnel era uma explosão sônica e uma vibração que incomodava os moradores de até 400 metros de distância do local. 0 problema estava no design do nariz do trem. O problema foi resolvido por Eiji Nakatsu, engenheiro e observador de pássaros, que se inspirou no voo do 
martim-pescador ${ }^{1}$. Esta ave ao mergulhar para se alimentar, troca subitamente de um ambiente de baixa resistência (ar) para um com muita resistência (água) sem, no entanto, produzir nenhum tipo de ruído, devido à sua aerodinâmica perfeita. Após remodelar o nariz do trem-bala com as similaridades do bico do martimpescador, os trens ficaram mais silenciosos e também 10\% mais rápido e $15 \%$ mais econômicos.

\section{Novas tecnologias aliadas à indústria aplicadas a preservação das espécies \\ A atividade industrial é} indispensável para o estilo de vida da sociedade do século XXI, conquanto não é distante de se imaginar que há uma grande inquietação possibilitando reduzir os impactos da indústria sobre o meio ambiente desde meados da década de 1970, quando a poluição e a degradação ambiental passaram a ocupar as agendas dentro do panorama que procura resolver os problemas de saúde pública encontrados nesse período nos polos industriais.

As aceleradas alterações tecnológicas fomentadas pelo atual modelo capitalista de produção, extensivamente propagado no mundo, teve como resultado comportamentos sociais e hábitos de consumo intensificados pela grande perda de recursos naturais. Problemas estes, evidenciados por ocasião destes acontecimentos, colocam o tema da sustentabilidade num lugar de vanguarda, chamando a atenção de governos, organizações e comunidade acadêmica (Malhotra et al., 2013).

Assim, a Tecnologia da Informação (TI) é parte responsável e significativa dos problemas ambientais que entram em choque com a sociedade contemporânea (Murugesan, 2010).

\footnotetext{
${ }^{1}$ https://www.bbc.com/portuguese/geral42193691
}

Problemas gerados pelo grande consumo de energia (podendo contribuir para a emissão de gases do efeito estufa), a quantidade de insumos não renováveis utilizados na produção computadores, o descarte de equipamentos obsoletos são realidades notórias (Ozturk et al., 2011). Entretanto, a responsabilidade socioambiental começa a ser tema das empresas que necessitam sobreviver (Colwell e Joshi, 2013), além de que passa a obter vantagem competitiva (Porter e Linde, 1995). Com tal expectativa, o gerenciamento inteligente da TI surge como uma opção atrativa para as organizações, não apenas com a prerrogativa de minimizar os danos causados ao meio ambiente, mas, de certa maneira desenvolver um ambiente organizacional sustentável, em afinação com as demandas pró-sustentabilidade da sociedade do fim desta segunda década do século XXI ressoando em qualidade de vida, preservação de recursos naturais e vantagem competitiva (Melville, 2010; Orsato, 2006).

Conforme Lunardi et al. (2011), a TI Verde ainda é um movimento novo, contudo, não possui neste momento um conceito estoicamente definido, muito menos representa um conjunto predeterminado de estratégias aceitas e colocadas em prática por todas as organizações. Assim sendo, a Tecnologia de Informação Verde pode ser associada aos estudos de projetos, fabricação, utilização e descarte de produtos e subprodutos computacionais, prevendo efetividade com a intenção de garantir menores impactos negativos ao meio ambiente (Murugesan, 2010). Diante do exposto, é imprescindível que se dê atenção para uma conscientização frente ao desperdício, à economia da eficiência energética e ao custo total de propriedade, abrangendo o custo de descarte e reciclagem. Além de se demonstrar a aplicação de instrumentos para controlar, orientar e comunicar as práticas usadas (Schmidt et al., 2010). 
É relevante lançar o olhar para a TI Verde junto com uma abordagem holística e sistemática para encarar os desafios da infraestrutura de $\mathrm{TI}$, dos impactos ambientais das atividades de TI, do suporte de TI para as práticas empresariais ambientalmente corretas e do papel da TI na economia de baixo carbono (Molla et al., 2008). Com uma visão sociotécnica, Brooks et al. (2010) consideraram a TI Verde como:

(a) iniciativas que empregam a infraestrutura de TI na mudança de processos e/ou práticas organizacionais para melhorar a eficiência energética e reduzir os impactos ambientais; e

(b) produtos de TI ambientalmente corretos. Assim, a TI Verde pode colaborar para inserção de estratégias ambientalmente favoráveis nas organizações, bem como introduzir produtos ambientalmente corretos no mercado.

Há diversas maneiras de se utilizar as tecnologias em virtude da proteção ambiental. 0 tema é muito vasto para ser limitado, mas foram pesquisadas algumas tecnologias que serão favoráveis à preservação do meio ambiente, como:

a) Utilização dos satélites para controle de áreas desmatadas;

b) Uso de sistemas que avaliem o desempenho das ações socioambientais pelas organizações;

c) Desenvolvimento de programas informatizados que permitam à população interagir com os governos para informar e obter informações sobre questões ambientais;

d) Uso da internet para divulgação de ações individuais e/ou coletivas contra o ambiente;

e) Uso da internet para divulgação dos resultados positivos das ações em defesa do ambiente;

f) Controle e fiscalização dos processos que envolvam mecanismos de proteção ambiental. Por meio das tecnologias de informação e comunicação é possível, por exemplo, acessar mapas elaborados por meio de fotografias tiradas por satélites, o que facilita, sobremaneira, a fiscalização de áreas degradadas, desmatamentos e outras situações de grave prejuízo ecológico.

Como é lei que as organizações públicas e privadas desenvolvam ações socioambientais e de sustentabilidade, a fiscalização do cumprimento deve também ser feita via tecnologia da informação, como um meio avaliativo das ações neste sentido. Tal qual aponta Luño (2004):

El signo de nuestro tiempo se distingue por la omnipresencia de las nuevas tecnologias (NT) en todos los aspectos de la vida individual $\mathrm{y}$ coletiva. En los últimos años se ha ampliado decisivamente la incidência de las NT en amplios sectores de la expereciencia jurídica y política. Ello invita a plantear también su repercusión en el alcance y ejercicio de la ciudadania (Luño, 2004, p. 57).

A cidadania participativa funciona como um elo de comunicação entre o indivíduo e o governo numa aliança para a decisão integrativa. Neste sentido, há o princípio ou condição para se observar a prática da sociedade informatizada, conforme aponta Luño (2004):

[...] el reconociemiento del derecho de todos los ciudadanos, sin ningún tipo de discriminación o excepciones, a participar directamente en la decisión de los asuntos que les afectem" (Luño, 2004, p. 59).

\section{Conclusão}

Com base neste estudo desenvolvido com aspectos históricos sobre a relação do Homem com a Natureza, conclui-se que a lógica é o começo da solução para a transformação dos recursos do meio ambiente. Nota-se nas atividades de birdwaching que ainda é recente no Brasil, como o ser humano tem alterado e modificado as paisagens 
naturais, gerando a Crise Ambiental. É importante que as empresas passem a agregar em suas atividades recreativas, a educação ambiental voltada para o birdwaching ou observação da natureza, pois ver-se como possibilidade gerar o fomento de ideias para elaboração de projetos sustentáveis, a fim de que se preservem as espécies vivas e não comprometa a qualidade/garantia de vida das gerações futuras.

Acredita-se que a utilização da TI Verde nas empresas maiores, é uma estratégia eficiente para se valorizar produtos e serviços beneficiando o meio ambiente. Com a adoção dessa prática é possível adquirir certificações internacionais, como o ISO 14001. Essa certificação é responsável por medir o impacto de determinados negócios no meio ambiente. Assim, o investimento em TI Verde pode ser um diferencial para os clientes e um atrativo de mídia.

Em futuras pesquisas, serão desenvolvidos estudos quantitativos e qualitativos de identificação de aves, para se comparar os resultados advindos da atividade de birdwatching e observação da natureza, relacionando ao desenvolvimento do trabalho de TI Verde nas empresas pesquisadas com propósito de preservação ambiental. 0 trabalho partirá de algumas variáveis como: técnica de voo, camuflagens, associação com outras espécies, etc.

\section{Conflito de interesses}

Os autores declaram não haver conflito de interesses.

\section{Referências}

Abrão, B. S. (Org.). A História da Filosofia. São Paulo: Nova Cultural, 2004. (Coleção Os Pensadores).

Avila, P. U.; Oliveira, T. R.; Barbosa, W. Tecnologia e a interface: interação ser humano x máquina. São Paulo: USP, 2018.

Aristóteles. Organon. São Paulo: Nova Cultural, 2004. (Coleção Os Pensadores).
Arruda, F. 5 tecnologias inspiradas pela Natureza: Ciência. Tecmundo, 2011. Disponível em: <https://www.tecmundo. com.br/ciencia/12821-5-tecnologiasinspiradas-pela-natureza.htm $>$. Acesso em: 28 ago. 2018.

Bakhtin, M. O discurso no romance. In: Bakhtin, M. Questões de literatura e de estética: teoria do Romance. 6 ed. São Paulo: Hucitec, 2010.

Battestin, C.; Ghiggi, G. 0 que a filosofia tem a ver com a educação ambiental? Reflexões filosóficas. Revista Eletrônica em Gestão, Educação e Tecnologia Ambiental, v. 3, n. 3, p. 299-305, 2011. https://doi.org/10.5902/ 223611703294

Brooks P.; Harpold, A.; Somor, A.; Troch, P.; Gochis, D.; Ewers, B. E;. Pendall, E.; Biederman, J.; Reed, D.; Barnard, H.; Whitehouse, F.; Aston, T.; Borkhuu, B. Quantifying the effects of mountain pine beetle infestation on water and biogeochemical cycles at multiple spatial and temporal scales. AGU 2010, San Francisco, CA, 2010.

Capra, F. As conexões ocultas. São Paulo: Cultrix, 2003.

Colwell, S. R.; Joshi, A. W. Corporate ecological responsiveness: Antecedent effects of institutional pressure and top management commitment and their impact on organizational performance. Business Strategy and the Environment, v. 22, n. 2, p. 73-91, 2013. https://doi.org/10.1002/ bse.732

Costa, R. G. A. Observação de aves como ferramenta didática para Educação Ambiental. Revista Didática Sistêmica, v. 6, p. 33-44, 2007. https://doi.org/10.14295/ rds.v6i0.1239

Descartes, R. Discurso do método. São Paulo: Nova Cultura, 1999. (Coleção Os Pensadores).

Dowbor, L. Tecnologias do conhecimento: os desafios da educação. Petrópolis: Vozes, 2001.

Edens, F. W.; Garlich, J. D. Lead-induced egg production decrease in leghorn and Japanese quail hens. Polution Science, v. 62, n. 9, p.1757-1763, $1983 . \quad$ https://doi.org/ 10.3382/ps.0621757

Endrigo, E.; Develey, P. F. Aves da Grande São Paulo. 2. ed. Rio de Janeiro: Guia de Campo, 2011. 
Fernandes, C. P.; Steinwender, D.; Pimenta, E. Observação de aves (birdwatching) na Universidade Veiga de Almeida Campus Cabo Frio. Caderno PIC UVA, n. 9, p. 1-2, 2014. Disponível em: <http://ojs.uva.br/index.php? journal=pic\&page $=$ article\&op=view\&path[]= 247>. Acesso: 23 jul. 2018.

Ferreira, C. TI Verde 2.0: no caminho sustentável. Revista TI Inside, n. 53, p. 16-22, 2009.

Freitas, M. Física e meio ambiente: o substrato da estética na ciência contemporânea. Ciência e Cultura, v. 57, n. 3, p. 33-36, 2005. Disponível em: <http://cienciaecultura.bvs.br/pdf/cic/v57n 3/a17v57n3.pdf>. Acesso em: 27 ago. 2018.

Frisch, J. D.; Frisch, C. D. Aves brasileiras e plantas que as atraem. 3. ed. Rio de Janeiro: Guia de Campo, 2005.

Giacomini Filho, G. O meio ambiente e consumismo. São Paulo: Ed. Senac, 2008.

Gragnaniello, S. D.; Fulgione, M.; Milone, O.; Soppelsa, P.; Cacace, L.; Ferrara, L. Sparrows as possible heavy-metal biomonitors of polluted environments. Bulletim of Environmetal Contamination Toxicology, $\begin{array}{lll}\text { v. } 66, & \text { p. } 6, \quad \text { p. } 719-726, & 2001 .\end{array}$ https://doi.org/10.1007/s001280068

Grün, M. Ética e Educação Ambiental: a conexão necessária. Campinas: Papirus, 1996.

Heckler, E.; Back, S.; Massing, E. R. Dicionário morfológico da língua portuguesa. São Leopoldo: Unisinos, 1984. $4 \mathrm{v}$.

Heinz G. H. Selenium in birds. In: Beyer, W. N.; Heinz, G. H.; Redmon-Norwood, A. W. (Eds). Environmental contaminants in wildlife: Interpreting tissue concentrations. Boca Raton: CRC Press, 1996. p. 447-458.

Lepore, E.; Bosia, F.; Bonaccorso, F.; Matteo, B.; Taioli, S; Garberoglio, G.; Ferrari, A. C.; Pugno, N. M. Aranhas que ingerem grafeno e nanotubos tecem teias mais fortes. Jornal: Inovação Tecnológica, v. 4, n. 3, 2017. Disponível em: <https://www.inovacao tecnologica.com.br/noticias/noticia.php?arti go=aranhas-ingerem-grafeno-nanotubostecem-teias-mais-fortes\&id=010160170918 \&ebol=sim $>$. Acesso em: 27 ago. 2018.

Lunardi, G.; Frio, R.; Brum, M. Tecnologia da informação e sustentabilidade: levantamento das principais práticas verdes aplicadas à área de tecnologia. Gerais: Revista Interinstitucional de Psicologia, v. 4, n. 2, p.159-172, 2011. Disponível em: <http://pepsic.bvsalud.org/pdf/gerais/v4ns pe/v4nspea06.pdf>. Acesso em: 23 jul. 2018.

Luño, A.-E.P. Ciberciudadani@o ciudadani@.com? Barcelona: Gedisa, 2004.

Malhotra, A.; Melville, N. P.; Watson, R. T. Spurring impactful research on information systems for environmental sustainability. MIS Quarterly, v. 37, n. 4, p. 1265-1274, 2013. https://doi.org/10.25300/MISQ/ 2013/37:4.3

Melville, N. IS innovation for environmental sustainability. MIS Quarterly, v. 34, n. 1, p.1-21, 2010. Disponível em: <https://www.misq.org/downloadable/dow nload/linkSample/link_id/838/>. Acesso em: 23 jul. 2018.

Molla, A.; Abareshi, A. Organizational green motivations for information technology: Empirical study. Journal of Computer Information Systems, v. 52, n. 3, p. 92-102, 2012. https://doi.org/10.1080/08874417. 2012.11645562

Mountouris, A.; Voutsas, E.; Tassios, D. Bioconcentration of heavy metals in aquatic environments: the importance of bioavailability. Marine Pollution Bulletin, v. 44, p. 1136-1141, 2002. https://doi.org/ 10.1016/S0025-326X(02)00168-6

Mourão, R. M. F. Observação de Aves. Caderno de Subsídios Observação de Aves. In: MPE Funbio. Manual Melhores Práticas para o Ecoturismo. Rio de Janeiro: Programa MPE Funbio, 1999. p. 248-258.

Murugesan, S. Harnessing green IT: principles and practices. IT professional, v. 10 , n. 1 , p. $24-33$, 2008. https://doi.org/ 10.1109/MITP.2008.10

Murugesan, S. Making IT green. IEEE IT Professional, $\quad$ v. $12, \quad$ n. 2, p. 4-5, 2010. https://doi.org/10.1109/MITP.2010.60

Oliveira, T.R. Educação com base na propaganda para o ensino integrado da preservação do meio ambiente. Revista: Natural Resources, 2018.

Orsato, R. J. Competitive environmental strategies: When does it pay to be green? California Management Review, v. 48, n. 2, p. 127-143, 2006. https://doi.org/10.2307/ 41166341

Orsi, C. O mundo macroscópico, o voo dos pássaros e a física quântica. Jornal da UNICAMP, n. 634, 2015. Disponível em: <http://www.unicamp.br/unicamp/ju/634/ 
o-mundo-macroscopico-o-voo-dos-passarose-fisica-quantica>. Acesso em: 27 ago. 2018.

Ozturk, A.; Umit, K.; Medeni, I. T.; Ucuncu, B.; Caylan, M.; Akba, F.; Medeni, T. Green ICT (information and communication technologies): A review of academic and practitioner perspectives. International Journal of eBusiness and eGovernment Studies, v. 3, n.1, p.1-16, 2011. Disponível em: <http://dergipark.gov.tr/download/ article-file/257058>. Acesso em: 23 jul. 2018.

Pesso, K. S. Oficina de Educação Ambiental. Disponível em: <http://www.telecentros. sp.gov.br/capacitacao/apostilas/educaçãoambiental.pdf>. Acesso em: 23 jul. 2018.

Santaella, L. 0 que é semiótica. São Paulo: Brasiliense, 1983.

Schmidt, N.; Erek, K.; Kolbe, L.; Zarnekow, R. Predictors of green IT adoption: implications from an empirical investigation. Proceedings of the Americas Conference on Information Systems, Lima, Peru, 2010. 
Informação da Licença: Este é um artigo Open Access distribuído sob os termos da Licença Creative Commons Attribution, que permite uso irrestrito, distribuição e reprodução em qualquer meio, desde que a obra original seja devidamente citada. 